\title{
SOCIAL REPRESENTATIONS OF DISABILITY BY TEACHERS AND PARENTS: ANALYSIS OF THE CONTENT OF THEIR NARRATIONS
}

\author{
Giulia Savarese, PhD \\ Rosangela Cuoco, PhD \\ Ph.D. in "Methodology of educational research" \\ Professor of "Psychology of development and education" \\ Department of Medicine and Surgery, University of Salerno, Baronissi (Sa) \\ Ph.D. in "Methodology of educational research" \\ High School teacher \\ IIS “Santa Caterina da Siena” Salerno
}

\begin{abstract}
AIM: understand the social representations of disability in the school context

METODOLOGY: purpose-built questionnaire with open answers, consisting of 10 questions, was used.

RESULTS:

- the operators interviewed undoubtedly framed the disabled student in a non-medicalization perspective, albeit with qualitative differences;

- all teachers and all parents have de facto provided representative modalities that are often collusive between themselves;

- only the families of students with disabilities can provide significant information on therapeutic opportunities or previous educational experiences that may give relevant results in terms of both behaviour and profit.
\end{abstract}

Keywords: Handicap; social representations of disability; students with disabilities

\section{Introduction}

"Social representations are the mechanisms through which a community builds a system of values, ideas and behaviours around a social fact, whereby this system puts that fact into an already existing context, making it real for everybody" (Palmonari et al, 2002, p. 39). They affect people's behaviour, the social images that group or individual has of a particular social phenomenon. It is, therefore, interesting to investigate the social representations of disability and how they can be of hindrance or 
support to the inclusion (Pattanaik, 2010). Among others, the emotional and sexual dimensions of the disabled are symptomatic of the representational stereotypies of the social context, which do not identify them as normal developmental milestones and indicators of adulthood (Bozuffi, 2006).

It is possible to make a few observations also in the school context. The objective evaluation of judgment on the capabilities, of request of performance, of comparison and rivalry with classmates, but above all the effort of adaptation and socialization skills, in a still little habitual context, does not generally favour the school adjustment of children with disabilities. This makes the task of the companions more difficult and especially harder for the teacher to help them integrate. These difficulties are partially exacerbated by the degree of awareness that the child has of his/her diversity and the role of the family, which is often not fully integrated in the process of inclusion of the child at school. Sometimes, because of this, the disabled show at school their discomfort with psycho-emotional blocks or psychomotor restlessness or with an aggressive behaviour, especially when anxiety or fear are evident in themselves. Therefore, all these problems have a negative impact on the process of socialization and school inclusion of the disabled person (Savarese, 2009).

Literature also tells us that, in classes where disabled students are added, their typically developing classmates rarely - if ever - spontaneously interact with them and choose them as playing and study partners (Note, Soresi, 2007). It is interesting to understand, therefore, how reference adults read and represent all of the above dynamics. Federici and collaborators, through focus groups with main and support teachers, parents, health workers and educators, have conducted qualitative text and manual-based analyses, also with the help of the software called Atlas.ti. They have focused on representational models of disability identified in literature, such as social, medical and bio-psycho-social, concluding that the social model is widespread in all homogeneous groups by position, except for the group of support teachers. However, only the parents of the disabled and their teachers seem to strongly assert their commitment to a social model. In fact, the parents of non-disabled range between the social model and the medical model, while support teachers show an oscillation among all three models of disability. Finally, the bio-psycho-social model does not prevail in any group (Federici et al., 2006).

In literature, there are few studies using the methodology of qualitative analysis of text analysis, aimed at the investigation of the representations of the different actors involved in the processes of school inclusion, but we have found no study that compares teachers and parents' narrative content in such perspective. 


\section{Objective and hypothesis of research}

The aim of this study was to examine the social representations of disability by teachers and parents of children with and without disabilities, to explore the ways in which the inclusion of the disabled student is realised within the school context, by highlighting also the relational dynamics that drive the different individuals (main teachers, support teachers, parents with and without disabled children), sharing the same context of inclusion.

The assumption is that main teachers, support teachers, parents with disabled children and those with typically developing children can sometimes produce representative modalities, which collide with each other and create the emergence of cultural repertoires that make living together more or less complex and diverse organizationally.

\section{Methodology}

The research was conducted on a sample (cluster sampling) from Salerno and its province, consisting of:

Group of teachers: 149 main teachers, 139 support teachers of various levels, equal number of males and females aged between 30 and 60 . Group of parents: 167, including 40 parents of disabled students, equal number of males and females aged between 30 and 50 .

A purpose-built questionnaire with open answers, consisting of 10 questions, was used.

The questionnaire was given to participants at the schools to which they belong, after a meeting with the researchers, which presented the research and clarified any doubt about the interpretation of the questions. The completion occurred at the homes of the respondents.

The completion time was about two hours.

Regarding the procedures of data analysis, a textual analysis was conducted with the help of the T-LAB software (Lancia, 2005). We chose this testing procedure, often used in psychological research for some years, to minimize our intervention on respondents, also because the material to be analysed had long phases of collection and physiological delays, with the risk of having to keep under control many intervening variables. Being aware that this type of analysis presents the disadvantage that the researcher can be too active in the interpretation of the data, we have developed a research plan that would use a software, the aforementioned T-LAB, which also takes into account the semantics of the analysed corpus.

The variables examined were:

- Gender and age for the entire sample;

- For the group of teachers: if support or main teachers, length of service and level of the school they belong to; 
- For the group of parents: whether with or without disabled children, occupation and level of education.

\section{Discussion of main results}

By means of a $\mathrm{T}$ test for independent samples, significant differences in the comparison between the responses of main teachers and support teachers were not shown, as well as between the responses of parents with disabled children and those without children with disabilities. However, significant ( $>>.05)$ were the responses in the groups teachers (all, main and support) and parents (all, with and without children with disabilities), and we present the resulting data.

The other examined variables showed no significant differences.

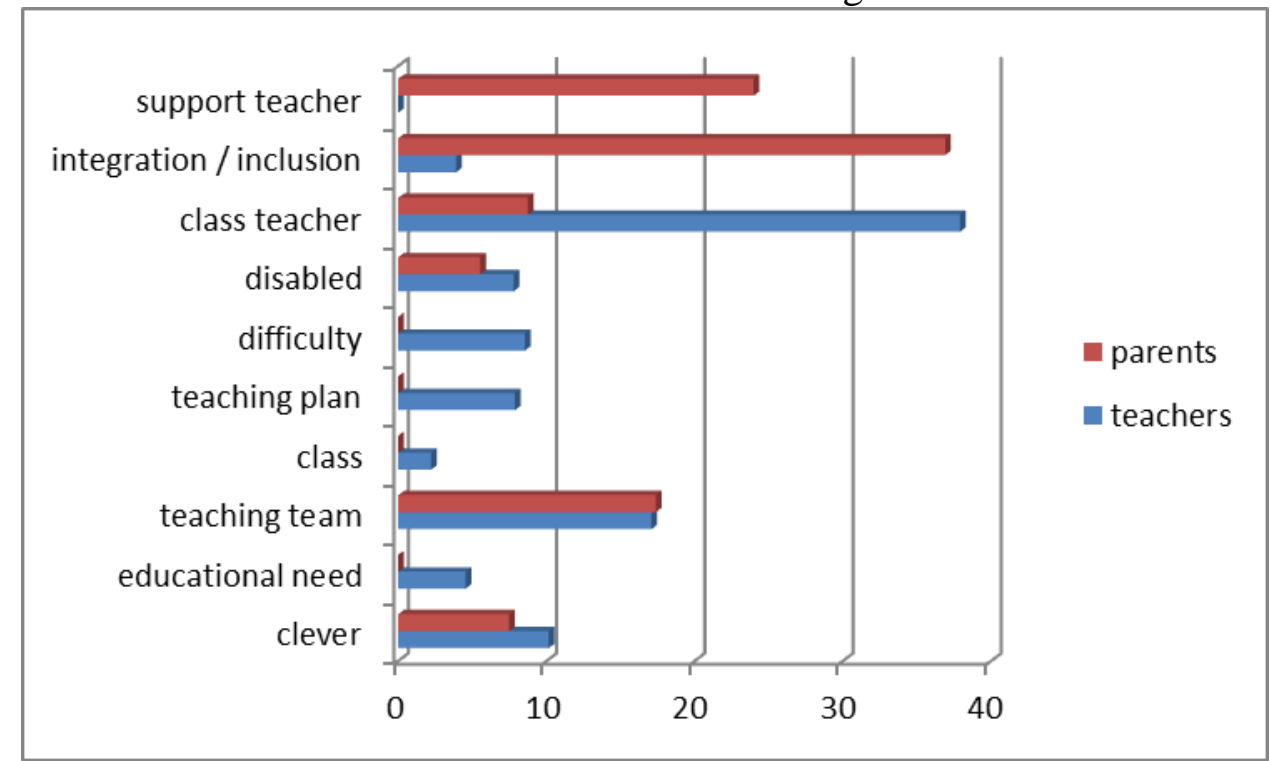

Graph 1: Associations of words at the re-occurrence of the terms "student" and "disability" (data in \%)

During the associations of words (Graph. 1), the teachers intended disability as a special educational need, also common to other students. Therefore, they consider students with disabilities as belonging to the class and as individuals for whom to prepare individualised and flexible programs, which should facilitate the inclusion process. They believe that all teachers should work together in order to commonly define "shared objectives" (i.e. processed and actualised together targets, not just imposed), possible routes, criteria for monitoring and evaluation of both the targets and the methods to achieve them (Savarese, 2009). They think, therefore, of the fundamental role of the teaching team for the integration and inclusion in schools, in synergy with the valorisation of the role of classmates. They do, however, 
never refer to the importance of the cooperation of the families in these paths.

As for the parents, however, it should be noted that they do not think of particular struggles/difficulties, when it comes to students with disabilities; they have as a reference, in the first place, the support teacher and, only in a second moment, main teachers. In fact, in most cases, the parents, while giving the school institution the difficult task of inclusion / integration, consider the support teacher as the only one capable of really taking charge of the disabled student and of the objectives the student will achieve through the personalization of education. Although the need for a debate and a dialogue between parents and teachers is obvious, the analysis of our data leads to assert, however, that parents consider the school still resistant to realize the full involvement of the family of the student with a disability.

A very interesting aspect, in our view, is the absence of reference to the resource of classmates from both groups surveyed.

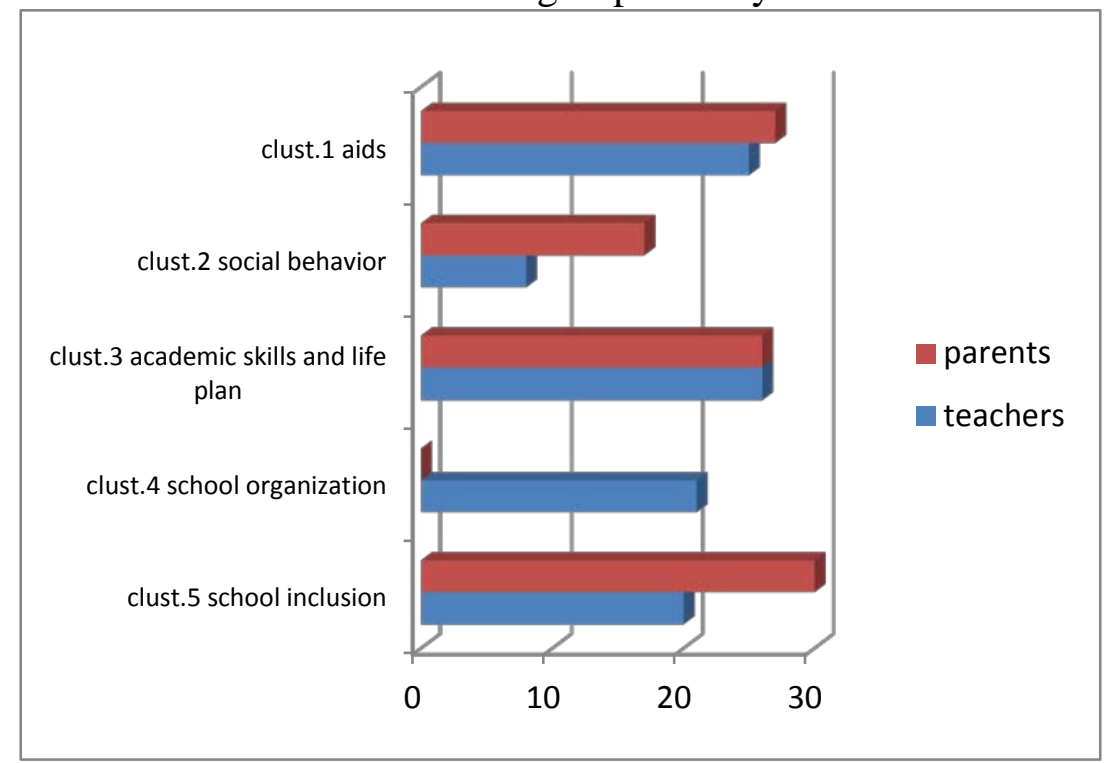

Graph 2: Cluster analysis (data in \%)

We then identified five clusters (Graph 2), which show how the problems of social inclusion and education of the students with disabilities are mostly felt by the group of parents, because of the barriers still in existence in architectural, mental and social terms. In fact, among the most significant lemmas appear "school", "accessible", "type", "handicap", "report/relationship" and "to favour".

Teachers, however, point out especially the inclusion of disability issues, highlighting in particular the complexity of the school system, which 
has to deal in parallel with individualized activities, involvement of all pupils, special educational needs and co-existence of the whole class group. In fact, among the most significant lemmas appear "group", "activity", "class", "to favour", "school”, "to involve”, "inclusion”, "to integrate” and "class group.”

\section{Conclusion}

Our study objective was to understand the social representations of disability in the school context. All the operators interviewed undoubtedly framed the disabled student in a non-medicalization perspective, albeit with qualitative differences, depending on the role played, whether as a teacher or parent. Our hypothesis was only partially verified. In fact, in contrast to what we were expecting, main and support teachers, as well as parents with and without children with disabilities, all provided similar representations; however, all teachers and all parents have de facto provided representative modalities that are often collusive between themselves. This, of course, makes the organizational coexistence complex and it often penalizes or delays inclusion paths for students with disabilities. It becomes clear how scarce is the centrality of the report between school and family in the integration process. Yet, for the growth and social maturity of the disabled student, event teachers need the information and directions that only the family can offer. In fact, only the families of students with disabilities can provide significant information on therapeutic opportunities or previous educational experiences that may give relevant results in terms of both behaviour and profit. The school could be the best environment to achieve this path, which should represent the primary goal of a real inclusion process, a process that requires the synergy between teachers and parents in a social network of shared responsibilities, in a continuous exchange of information and advice and with a consistent transition of leadership depending on the type of problem to be addressed (Stainback, Stainback, 1993; Dionne and Rousseau, 2006).

We seem to be able to conclude that our data suggest the need to network: in line with recent international literature (Whittaker, Garbarino, 1983; Bigby, 2003; Chenoweth, McAuliffe, 2005), school inclusion is a process that implies the need for integrated team work and social network, having as objective the guarantee of an educational offer which is functional to the full development of the individual potentials (Zanobini, Usai, 2005). Making a school tailored to the learning needs of each student implies, especially for students with disabilities, an indispensable synergy with families and the environment outside school, to allow the individualisation of the actual schooling, directing the Individualised Education Plan to a dimension of life plan (Cuoco, 2009; 2012). 
From the methodological point of view and operational, it is necessary to move from the logic of individual support to the network of supports (Cuoco, Savarese, 2010), formed both by the school operators and the external resources.

From these considerations, it is also clear that the isolated intervention becomes less than satisfactory for the disabled pupils' life plan and, of course for actions that relate to the school inclusion, too.

While building relationships among main teachers, support teachers and families can be tiring, and at times quite difficult, it is clear that only by organizing the school life in all its components, according to the model of the network of supports and, in our opinion, also of resources, a school that values differences, responding to the educational needs of each student, can be realised (Ianes, 2000). Within the social network, we must not forget also the disabled individual's classmates, an undoubtedly valuable resource (Vianello et al., 1999; Savarese, 2009). In fact, studies conducted with adolescent students who experienced a school environment with the presence of classmates with moderate or severe mental delays, have allowed us to demonstrate that prolonged contact with comrades who have special needs brings benefits both on the cognitive, affective-emotional and social aspects. In particular, we have highlighted six different types of benefits that the surveyed students have taken from their relationship with "special" peers (Savarese and Iannaccone, 2010):

1. Improvement of the concept of self;

2. Greater interpersonal understanding;

3. Lesser fear of differences;

4. Greater tolerance;

5. Development of personal principles;

6. Experience of genuine acceptance.

A thorny issue, and apparently still unresolved, concerns then the consideration of the teacher support, by the public opinion, as the only deputy to educate / teach the student with disabilities (Scruggs, Mastropieri, 2005). This belief, in truth, has also been reported by some (few) of our interviewed teacher with greater seniority. Yet, in all ministerial documents, from 1975 onwards, the support teachers have been considered a "support to the class", whose ability is to network their communication skills with those of other teachers to coordinate different levels of educational planning, including the personalised education plan for the disabled student (Ianes, 2000; Ianes 2006). Furthermore, the Ministerial Directive of 27/12/2012 highlighted the strategies to achieve the right to learn for pupils with difficulties, providing greater scope for intervention not only for pupils with Specific Learning Disorders (SLD), implemented by Law no. 170/2010, but also the entire area of Special Educational Needs (SEN) (Ministerial Circular 
no. 8/2013), such as specific developmental disorders, linguistic, social and cultural disadvantages. It extends, therefore, to all students in need the right to personalised learning, referring to the principles of the Law 52/2003. In this perspective, the majority of pupils is to be considered with special educational needs, no longer only the disabled. Then the prejudice of teacher being "special", the support, as "special" is his pupil, the disabled, should disappear. In the light of recent legislation, instead, the majority of students are seen as "special" and, if a teacher is forced to operate by himself, the institutional design of the SEN not only has less chance of success, but also is likely to fail miserably. The Law regarding SEN is also innovative in this respect, since it no longer refers to a specialist teacher, but to a team of specialised teachers, meaning, in this regard, both the main teachers and the support, in a synergic work. The Law also wishes to witness a real involvement of the Teachers Board and School Committees to achieve the adoption of an internal school policy for the inclusion, which takes a real transversality and centrality of the complex of the educational offer. The real policy (Various Authors, 2006; Giombattista, 2009), in this sense, can only be achieved if the families of students with SEN will be considered active parties to contribute to the development of adequate and timely educational services and whether the school will use in case of real need, even outside consultants (Ministerial Circular no. 8/2013). Thus, the aforementioned network of supports requires mutual support between institutions and communities, and the interpretation of differences as a resource and not as problems to be solved.

\section{References:}

AA.VV (2006), Disabilità e politiche sociali, Milano, Franco Angeli.

Bigby C. (2003), Ageing with a lifelong disability: a guide to practice, program and policy issues for human services professionals, Jessica Kingsley Publishers, London.

Bozuffi V. (2006), Psicologia dell'integrazione sociale. La vita della persona con disabilità in una società plurale, Milano, Franco Angeli.

Chenoweth L. e McAuliffe D. (2005), The road to social work \& human service practice: an introductory text, Thomson Learning, Southbank Victoria.

Circolare Ministeriale 6/3/2013, n. 8 "Strumenti d'intervento per alunni con bisogni educativi speciali (BES)"

Cuoco R. (2009), «La rappresentazione della disabilità negli insegnanti», Quaderni del Dipartimento 2008-2009 - Università di Salerno, II, 253-265.

Cuoco R. (2012), Docenti genitori e rappresentazioni della disabilità: una ricerca con l'ausilio dell'analisi del testo, Tesi di Dottorato, Università di Salerno. 
Cuoco R. e Savarese G. (2010), «La disabilità nella scuola superiore: professionalità docente, problematiche educative e dinamiche relazionali», Quaderni del Dipartimento 2009-2010 - Università di Salerno, II (II), 163187.

D. M. 27/12/2012, "Strumenti d'intervento per alunni con bisogni educativi speciali e organizzazione territoriale per l'inclusione scolastica»".

Dionne C. e Rousseau N. (2006) (Eds.), «Trasformation des pratiques éducatives», La recherche sur l'inclusion scolaire, 159-180.

Federici S., Meloni F., Brogioni A., Lo Presti A. (2006), «Analisi qualitativa dei modelli di disabilità: la prospettiva di genitori, insegnanti e educatori professionali», Ciclo Evolutivo e Disabilità/Life Span and Disability, 2, 197224.

Giombattista G. (2009), Disabilità psichiatrica e lavoro: un binomio possibile? Politiche sociosanitarie, governance territoriale e inclusione lavorativa, Milano, Franco Angeli.

Ianes D. (2000), Didattica speciale per l'integrazione, Trento, Erickson.

Ianes D. (2006), «The italian model for the inclusion and integration of students with special needs: some issues», Trans. Jour. Phys. Sup., I, 117127.

Lancia F. (2005), Strumenti per l'analisi dei testi, Milano, Franco Angeli.

Nota L. e Soresi S. (2007), La facilitazione dell'integrazione, in Soresi S., Psicologia delle disabilità, Bologna, Il Mulino.

Palmonari A., Cavazza N. e Rubini M. (2002), Psicologia sociale, Bologna, Il Mulino.

Pattanaik D. (2010), Reorienting social representation and disability: perspectives on everyday life and community, Saarbrücken, VDM Publishing.

Savarese G. (2009), Io e il mio amico disabile, Milano, Franco Angeli Editore.

Savarese G. e Iannaccone A. (a cura di) (2010), Educare alla diversità, Milano, Franco Angeli Editore.

Scruggs T.E. e Mastropieri M.A. (2005), Advances in learning disabilities, Oxford, UK: Elsevier Science/JAI Press, 147-160.

Stainback W. e Stainback S. (1993), La gestione avanzata dell'integrazione scolastica. Nuove reti organizzative per il sostegno, Trento, Erickson.

Whittaker J. K. e Garbarino J. (1983), Social support networks: informal helping in the human services, Aldine Transaction, New York.

Zanobini M. e Usai M. (2005), Psicologia della disabilità e della riabilitazione, Milano, Franco Angeli Editore. 